\title{
Livro didático e memória - a construção do saber escolar sobre a História de Santa Catarina nas primeiras décadas do século $X X^{1}$
}

\author{
Cristiani Bereta da Silva* \\ Helena Gabriela Moellmann Gasparini**
}

Resumo: Quais acontecimentos, personagens, recortes temporais, perspectivas, imagens, enfim, memórias sobre a história de Santa Catarina vêm sendo privilegiadas - em detrimento de outras - nos livros didáticos de História? O presente trabalho discute a construção de memórias sobre heróis e mitos catarinenses nos livros didáticos de História que foram produzidos e circularam nas décadas de 1920 a 1950 em Santa Catarina. Esse esforço pretende contribuir para dotar de inteligibilidade a própria trajetória do ensino de história de Santa Catarina, evidenciando, em sua historicidade, as formas de apropriação e construção do conhecimento histórico escolar em suas permanências e descontinuidades e, sobretudo, quais os pertencimentos, as identidades, as memórias que foram construídas nesse processo. A discussão proposta, aqui, é recorte da pesquisa "A História de Santa Catarina nos livros didáticos de História e a construção do saber escolar", que vem sendo desenvolvida com bolsa de iniciação científica e que se propõe investigar, numa análise de longa duração, as relações estabelecidas - em suas aproximações

1 Versão ampliada e modificada de texto apresentado no Grupo de Trabalho Livros Didáticos e Paradidáticos no VII Encontro Nacional Perspectivas do Ensino de História, realizado na Universidade Federal de Uberlândia, no período de 03 a 06 de novembro de 2009.

* Doutora em História Cultural. Professora Associada do Departamento e do Programa de Pós-Graduação em História da Universidade do Estado de Santa Catarina - UDESC. Coordenadora do Grupo de Pesquisa: Ensino de História, memória e culturas vinculado ao Núcleo de Ensino de História - NEH/UDESC. E-mail: cristianiluiz@hotmail.com

** Licenciada e bacharel em História (UDESC). Pesquisadora do Grupo de Pesquisa: Ensino de História, memória e culturas vinculado ao Núcleo de Ensino de História - NEH/UDESC. E-mail: lenynha@gmail.com 
e distanciamentos - entre a produção historiográfica e a produção de uma história de Santa Catarina para o uso escolar.

Palavras-chave: Memória, Livros didáticos, Saber histórico escolar.

\begin{abstract}
Which facts, characters, period, perspective, images and memories about the state of Santa Catarina have been privileged in History textbooks? This article discusses the construction of a memory about heroes and myths in Santa Catarina through the History schoolbooks produced and used in the state from 1920 to 1950 . This effort intends to contribute to the understanding of the history of education in the state, revealing ways of appropriation and construction of the historical knowledge inside the schools and considering its permanencies, discontinuities and, above all, the attachments, identities and memories developed in the process. This discussion is part of the research "The history of Santa Catarina in the History textbooks and the construction of knowledge in schools", which is being currently developed with governmental grant. Its aim is to investigate the relationships - similarities and differences- between the historiographic production and the production of a history of the state inside the schools.
\end{abstract}

Keywords: Memory, Textbooks, Historical knowledge in schools.

Os livros didáticos não são apenas instrumentos pedagógicos: são também produtos de grupos sociais que procuram, por intermédio deles, perpetuar suas identidades, seus valores, suas tradições, suas culturas.

Alain Chopin

A escolha dos livros didáticos para pensar a construção do saber histórico escolar deve-se à evidência de que o livro didático não necessariamente acompanha um determinado programa curricular; às vezes e, sobretudo, nas primeiras décadas do século 
$\mathrm{XX}$, é o livro didático que constrói e legitima o que deve ser ensinado, lembrado e, assim, legado como memória às geraçôes futuras. Claro que isso não se dá de forma fixa, linear ou mesmo sem disputas; há negociações e reelaborações constantes nesse processo de seleção que varia com os contextos e tempos ao longo da história. Do mesmo modo que, na condição de prescrição tanto os livros didáticos quanto os currículos normativos - não devem ser tomados como aquilo que se efetiva na sala de aula como um conjunto de normas e práticas. A cultura escolar possui suas próprias operaçôes definindo os conhecimentos a serem ensinados, os quais, também variam, segundo o tempo e finalidades específicas (JULIA, 2001).

Dito isso, não há como negar o fato de que os livros didáticos de História são suportes de memória que contribuem para a fixação de sentidos sobre determinados acontecimentos, possibilitando, ao pesquisador, analisar o campo de disputas sobre as memórias que cada sociedade deseja preservar e quais pretende esquecer. Assim como os demais produtos culturais que circulam nas escolas, os livros didáticos também produzem o social, o cultural e o político, contribuindo substancialmente para a construção e evidência, nas escolas e no cotidiano, de um "cenário onde as sociedades disputam as memórias possíveis sobre si mesmas" (CARRETERO, 2007, p. 14). Sua utilização, especialmente no contexto do final do século XIX e início do XX, contribuiu para a elaboração e legitimação de certos ideais de nação e cidadania. Esta perspectiva põe em relevo a estreita relação entre a escrita e uso de produções didáticas e a composição da História como disciplina escolar, conforme lembra Arlette Gasparello:

Os livros didáticos de História do Brasil, profundamente inscritos no processo de escolarização, contribuíram, em sua expressão pedagógica, na construção das identidades nacionais. Sob a chancela do poder público, como veículos privilegiados dos saberes a serem ensinados, os livros escolares firmaram-se como instrumentos pedagógicos cada vez mais utilizados por professores e alunos. Seu uso sistemático construiu memória e consolidou em tradição o vínculo "natural" entre escola e livro didático (GASPARELLO, 2004, p. 18). 
Além disso, não se pode prescindir do fato de que os livros didáticos são importantes mediadores e produtores de 'identidades', instrumentos de difusão e consolidação de elementos que conformam uma memória coletiva. Os livros didáticos utilizados em sala de aula, assim como as seleções de conteúdos a serem ensinados, produzem uma determinada História, pois é inegável que "atuam como mediadores entre concepçôes e práticas políticas culturais, tornando-se parte importante da engrenagem de manutenção de determinadas visões de mundo e de história" (FONSECA, 2006, p. 73).

A História não nasce pronta. Os fatos históricos não são meros reflexos discursivos dos acontecimentos, mas a construção e resultado de uma prática (historiadora). Partindo dessas premissas, pensamos as produçóes didáticas a partir de perspectivas colocadas pela História Cultural. Nosso objetivo se aproxima da idéia de pensar e "identificar o modo como em diferentes lugares e momentos uma determinada realidade social é construída, pensada, dada a ler" (CHARTIER, 1990, p. 16-17). Entendemos representação como o produto e produtor de práticas. A produção didática, por exemplo, constitui-se em representação à medida que é o produto de uma prática simbólica que se transforma em outras representações. Seja qual for o discurso e seu suporte, o que temos são sempre representações (CHARTIER, 1990). Ou seja, referimonos a um conjunto de ordenações simbólicas que permitem, não só significar a realidade, mas, fundamentalmente, produzi-la. Esse pressuposto nos faz pensar na própria construção de uma história catarinense e em sua divulgação. Ao nos debruçarmos sobre a escrita da história de Santa Catarina, nas primeiras décadas do século $\mathrm{XX}$, observamos que determinados momentos inaugurais foram escolhidos - em detrimentos de outros - para 'fundar' uma história dita catarinense, a qual foi construída e reconstruída em consonância com certos discursos políticos dominantes, no interior de determinados contextos históricos específicos e, ao mesmo tempo, articulados à história nacional que se forjava e reconstruía na recém inaugurada república brasileira. 
O período que decorre do fim do século XIX até as primeiras décadas do século XX converge para a produção de um novo discurso político em que "a história, ao lado da geografia e da língua pátria, tinha um lugar estratégico” (GOMES, 2009, p. 85). A escrita da História - a História Pátria - é produzida num contexto políticoideológico em que a educação cívico-patriótica emerge como eixo central. Em seu trabalho sobre a relação entre a república, a escrita da História e o Instituto Histórico e Geográfico Brasileiro, a historiadora Ângela de Castro Gomes (2009, p. 85) destaca que o peso alcançado pela educação cívico-patriótica no Brasil (e também em Portugal) possibilita o entendimento do envolvimento de um grupo variado e amplo de intelectuais que chamou para si a tarefa de pensar a república e a educação. Importante notar que a construção do saber histórico esteve, naquele momento, inextricavelmente ligada à preocupação de se construir uma "disciplina de História ensinável". Afinal, inventava-se um novo passado histórico nacional, o qual precisava atingir e mobilizar um grande público que precisava ser ensinado.

Em Santa Catarina, as tarefas de pensar sua história bem como construir uma narrativa sobre o Estado que pudesse ser objeto de ensino, nas primeiras décadas do século XX, foram realizadas sob forte influência dos intelectuais e políticos que compunham a "sociedade do discurso" (GOMES, 2009, p. 65) catarinense, ou seja, o Instituto Histórico e Geográfico de Santa Catarina. Guardando as devidas especificidades, grosso modo podemos dizer que essa relação replica aquela mantida entre o Instituto Histórico Geográfico Brasileiro e a História como disciplina escolar, evidenciada em diferentes pesquisas realizadas (FONSECA, 2006; GASPARELLO, 2004; BITTENCOURT, 1993; 2005; 2008; ABUD, 2005). Assim como ocorreu na cidade do Rio de Janeiro: forte associação entre a história dita acadêmica e a escolar. Ou seja, a história produzida pelo IHGB passava às salas de aula por meio de livros didáticos, muitas vezes escritos pelos próprios membros do Instituto que, por sua vez, também exerciam o papel de professores da disciplina (FONSECA, 
2006, p. 46). Nas primeiras décadas do século XX, a escrita da História que poderia fornecer os suportes para os programas curriculares de Santa Catarina, foi, em sua maioria, produzida pela elite intelectual que fazia parte do Instituto catarinense.

O Instituto Histórico e Geográfico de Santa Catarina foi fundado por José Arthur Boiteux (1864-1934) em 1896. Consta, porém, que o Instituto teria sido instalado em 17 de novembro de 1894, dois anos antes da data oficialmente aceita, no palácio do governo com a presença do governador Hercílio da Luz e outros tantos políticos e intelectuais influentes do Estado (CORREA, 1997 , p. 84). Convém chamar a atenção para as sobreposições profissionais dos membros do IHGSC, no período, pois, os historiadores daquela época eram jornalistas, advogados, médicos, dentre outras profissões. Mas, além dessas sobreposições profissionais, os membros do IHGSC mantinham relações estreitas com a política, alguns, inclusive, exercendo cargos importantes no executivo do governo estadual ou mandatos eletivos, configurando "uma situação de muita indistinção entre campo intelectual e político" (GOMES, 2009, p. 66), comum na época.

Pensar a construção e divulgação da história escolar sobre Santa Catarina implica refletir sobre algumas questões importantes. Primeiro: quais os lugares dessa produção? Quem a produziu nas primeiras décadas do século XX e quais foram as condições dessa produção? Segundo: quando ela passou a ser importante para ser ensinada? Como foi ensinada? Quais recortes foram feitos e sob quais condições foram realizados? Articulados a quais processos políticos culturais? Como a história escolar de Santa Catarina foi divulgada, dada a ler?

As fontes sobre as quais nos debruçamos, até o momento, dizem respeito às produções didáticas, programas de ensino, leis e decretos. Documentos normativos e prescritivos, portanto. Estamos cientes de que para responder as questóes levantadas, de modo satisfatório, precisaríamos coligir esses documentos com outro conjunto de fontes que nos aproximasse daquilo que foi efetivado no cotidiano da sala de aula, tais como cadernos escolares, diários, planos de aula, 
atividades, provas e/ou exames etc. Fica o desafio para o prosseguimento dessa e de outras pesquisas, pois, neste artigo, tentaremos esboçar algumas respostas possíveis - mesmo que parciais - sob os critérios e limites estabelecidos pelos documentos investigados.

\section{O ensino de História de Santa Catarina}

Em Santa Catarina, a produção didática só pode ser acompanhada quando observamos a própria organização de um sistema educacional no Estado, que se deu apenas nas primeiras décadas do século XX. É possível observar que o ensino de História fazia parte dos programas dos poucos liceus existentes no Estado, já no final do século XIX, conforme indica a obra de Primitivo Moacyr, sobre a criação das cadeiras de latim, francês, inglês, matemática, história e geografia, retórica e poética etc. para o recém restaurado liceu Ateneu provincial em 1875 (1940, p. 395). Em 1905, a fundação do Ginásio Catarinense em Florianópolis, o único que proporcionava escolarização secundária de forma regular e seriada, no Estado, durante a primeira república, também possuía a cadeira de história em seu programa (DALLABRIDA, 2001). Porém, a história da educação em Santa Catarina evidencia o quão podia ser frágil esse ensino, se levarmos em conta a própria organização de um efetivo sistema educacional no Estado. Segundo Fiori (1991) - ainda no fim do período imperial - havia uma deficiência no ensino público e privado em Santa Catarina, bem como uma necessidade de se organizar um projeto completo de reforma da instrução pública. Chamamos a atenção que, embora o ensino obrigatório tenha sido estabelecido, ainda em 1886, "onde houvesse escolas públicas", e um quarto da renda da Província fosse destinada para a instrução

2 Lei n.1.144 de 30 de setembro de 1886. Arquivo Assembléia Legislativa do Estado de Santa Catarina em Florianópolis. 
pública primária, ${ }^{3}$ é correto afirmar que a instrução pública, em Santa Catarina, só seria instituída, decisivamente, em 1911, no governo de Vidal Ramos.

A reforma do ensino em Santa Catarina proposta e efetuada, a partir do governo de Vidal Ramos, fez-se pelas mãos de Orestes Guimarães, professor e educador do Estado de São Paulo, lugar de referência nacional no quesito educacional naquele momento histórico. Havia, no Estado catarinense, uma alta taxa de analfabetismo e um expressivo problema em assimilar as muitas populações estrangeiras que o colonizavam desde meados do século XIX.

O principal diferencial apontado na reforma de Orestes Guimarães, segundo Fiori (1991), é que este, em vez de iniciar sua reforma construindo uma superestrutura administrativa, fê-lo justamente pelos ramos essenciais da estrutura em si, pelos próprios estabelecimentos de ensino. Dessa forma, através de uma estratégia presencial e reformadora, começando pelas instituiçôes espalhadas pelo Estado, buscou uma maior eficácia do que se estivesse centralizado em um gabinete administrativo, traçando metas distantes da realidade vivida pelos estabelecimentos individualmente.

O professor Orestes possuía uma personalidade forte e, segundo Neide Fiori, esta foi uma das características que mais marcou suas ações reformadoras no ensino catarinense. Posicionava-se contra o empreguismo e contra o apadrinhamento político, práticas, muitas vezes, presentes no contexto do início do século XX em Santa Catarina. Sua presença física durante as inspeções escolares era fator importante, já que, em sua opinião, a cobrança de resultados, desta forma, tornava-se mais eficaz. Além disso, propôs uma nova estruturação dos estabelecimentos de ensino: escola normal, grupo escolar, escola isolada, escola reunida e escola complementar. Através destas subdivisões, ações específicas e atenções diferenciadas eram possibilitadas aos diferentes estágios de ensino.

Relatório do Sr. Coronel Augusto e Souza. Abertura da $1^{\text {a }}$ Sessão da $27^{\text {a }}$ legislatura da Assembléia Provincial em $1^{\circ}$ de setembro de 1888. Desterro (SC). 
"A reforma de ensino do ano de 1911 proibiu aos alunos decorarem compêndios ou mesmo apontamentos fornecidos ou ditados pelos professores” (FIORI, 1991, p. 110). Assim, percebe-se que as novas concepções educacionais, então vigentes, buscavam uma nova metodologia de ensino, o que estimulou um novo relacionamento entre os materiais didáticos e os alunos. "Todo material escolar utilizado era determinado pelos órgãos dirigentes do ensino; o uso de qualquer outro material estava sujeito à detalhada justificação" (FIORI, 1991, p. 113). Ou seja, a atenção do governo estava voltada não apenas para os conteúdos que deveriam ser selecionados e ensinados, mas, também, para quais os veículos, os suportes de ensino seriam mobilizados para tal finalidade. Isso proporcionou uma série de transformaçốes no ensino catarinense. Faz-se importante ressaltar, ainda, que, apenas a partir de 1911 seriam construídos os primeiros programas de ensino pelo governo de Santa Catarina, de modo mais sistemático e abrangente, junto aos regulamentos da Instrução Pública decretados no período.

A organização de um sistema de ensino público, no Estado, demandou a criação de programas curriculares pouco mais sistematizados e de maior alcance, que, embora bastante voltados para a História do Brasil (em reconstrução, em seus aspectos simbólicos), apontavam também para a inserção de temas relacionados à história local e/ou regional. Pode-se dizer que a prescrição de se ensinar a história de Santa Catarina aos catarinenses remonta, pelo menos, ao ano de 1920. É o que informa o Programa de Ensino para os Grupos Escolares do Estado, ${ }^{4}$ que institui, já, a partir do segundo ano do Grupo Escolar, o ensino de história local. Há a necessidade de se estudar desde o próprio estabelecimento escolar, como sua inauguração, quem o fundou, referências a alunos do estabelecimento que "se distinguiram na vida prática" etc., até questões locais mais específicas como "Ligeira notícia sobre a fundação e a história da localidade; Dificuldades vencidas pelos primeiros povoadores" (1920, p. 21).

4 Programa de ensino dos Grupos Escolares - Aprovado pelo decreto n. 1.322, de 29 de janeiro de 1920, Florianópolis, 1920. 
Convém observar, aí, a matriz dos ainda atuais currículos assentados nos chamados círculos concêntricos, os quais instituem que os alunos, para apreenderem noções de tempo e espaço, devem ser apresentados primeiramente ao mais próximo, ou seja, escola, bairro, família para, depois, partir para o mais distante (cidade, município, região e nação). Para o terceiro ano, o Programa dispõe sobre a necessidade de se dirigir estudos mais desenvolvidos sobre os primeiros povoadores do município; primeiros exploradores do Estado, incluindo "Criação das vilas de S. Francisco, Desterro, Laguna e Lages” (1920, p. 29). Dentre os aspectos da história nacional prescritos, os alunos deveriam conhecer traços biográficos de "vultos nacionais", tais como Cristóvão Colombo, Pedro Álvares Cabral e Thomé de Souza, incluindo também os "catarinenses ilustres".

Não por coincidência foi, em 1920, que seria publicado o que talvez seja o primeiro livro didático sobre a história de Santa Catarina, o livro Pequena História Catarinense de Lucas Alexandre Boiteux. O livro, ilustrado, foi adotado oficialmente para ser usado na Escola Normal Catarinense, segundo o decreto do governador Hercílio Pedro da Luz, de n. 1267 de 21 de julho de 1919. Esse decreto é reproduzido na abertura do livro:

O engenheiro civil Hercílio Pedro da Luz, vice-governador, no exercício do cargo de governador do Estado de Santa Catarina, considerando que na Escola Normal há necessidade de um compêndio da Historia de Santa Catarina e que segundo o parecer da Diretoria de Instrução Pública, a Pequena História Catarinense, escrita pelo Capitão-tenente Lucas Alexandre Boiteux, satisfaz plenamente as exigências do programa da mesma Escola, decreta:

Art. 1 Fica adotada, na Escola Normal Catarinense, a Pequena História de Santa Catarina do Capitão-tenente Lucas Alexandre Boiteux. ${ }^{5}$

Na sequência há pareceres de Henrique da Silva Fontes, diretor de instrução, e de Orestes Guimarães, Inspetor Geral de Ensino, dando conta de que o livro também seria adotado nos quartos

5 Optamos por realizar a adequação da grafia do século XIX e início do século XX, para as atuais normas da Língua Portuguesa. 
anos dos Grupos Escolares catarinenses. Esse processo informa que a escrita, o financiamento e a adoção oficial da Pequena História Catarinense remetem fortemente para o controle e interferência do Estado na produção didática (BITTENCOURT, 2008).

A Pequena História Catarinense é versão modificada do livro Notas para a História Catarinense, de 1912, também de Lucas Boiteux. Ou seja, é uma versão que foi didatizada para atingir outro público, distinto daquele ao qual se dirigia o livro de 1912. Interpretamos que esses dois livros representam parte do processo de didatização da História de Santa Catarina. Lucas Boiteux foi um dos primeiros a produzir um livro para uso didático, tarefa que ajudou na feitura de currículos em Santa Catarina, pois, conforme afirma Bittencourt (2008), num contexto nacional, no final do século XIX e nas primeiras décadas do século XX, os livros didáticos foram importantes mediadores da construção dos currículos e propostas escolares. Assim, estes indícios permitem supor a importância das obras de Lucas Alexandre Boiteux, neste sentido, pois, através dos seus esforços em produzir uma história propriamente catarinense, contribuiu consideravelmente para a construção de um saber escolar em Santa Catarina.

Lucas Alexandre Boiteux (1880-1966) foi almirante da Marinha e pertencente a uma família de intelectuais e políticos bastante proeminentes no Estado; seu irmão, José Arthur Boiteux, foi o fundador do Instituto Histórico e Geográfico de Santa Catarina e ocupou uma série de cargos públicos importantes. E, o próprio Lucas Alexandre Boiteux participou da comissão de demarcação de limites com o Estado do Paraná, entre 1918 e 1922 (CORREAA, 1997).

Sobre o envolvimento de Lucas Boiteux na escrita e divulgação da História catarinense, destacamos que ele - na condição de sócio do Instituto Histórico Geográfico de Santa Catarina também construiu sua trajetória comprometido com a história e a geografia da região, que envolvia tanto a recuperação de informaçôes julgadas pertinentes ao passado histórico e ao espaço geográfico quanto à divulgação da história do Estado, visando promover o espírito cívico e patriótico da população catarinense. 
Para os membros do Instituto, a escrita, mas, principalmente, a guarda de documentos sobre o Estado estava relacionada à manutenção da integridade territorial catarinense, a "pequena pátria". Para a historiadora Janice Gonçalves (2006, p. 88):

O Instituto, consequentemente, posicionava-se a favor da manutenção da integridade territorial catarinense (um dos elementos fundamentais da "pequena pátria", ao lado da sua "gente" e dos seus costumes e tradições), bem como da manutenção da unidade territorial brasileira. $\mathrm{O}$ interesse pelos costumes catarinenses (que, a partir de fins dos anos 1940, foi modulado para a pesquisa relacionada ao "folclore") e, mais antigo e fundamental, pelos documentos para a história de Santa Catarina, transmutou-se, em parte, em ações de defesa - no caso, de defesa do patrimônio cultural catarinense.

A definição dos limites do território de Santa Catarina teve repercussões importantes na própria escrita da história catarinense. Vale lembrar as disputas históricas em tempos mais recuados, como as havidas entre Portugal e Espanha; num segundo momento, entre Argentina e Brasil e, num terceiro momento, entre Paraná e Santa Catarina (Guerra do Contestado, 1912-1916). Reflexos dessas disputas podem ser percebidos na atuação política e intelectual dos membros do IHGSC, constituindo-se em índice importante da memória e história catarinense. Como conteúdo a ser ensinado aparece na Pequena História Catarinense, de Lucas Boiteux:

Um terço do território foi tenazmente disputado pelo Paraná, muito embora luminosos acórdãos do Supremo Tribunal Federal houvessem proclamado o nosso direito. Esse território contestado havia sido acrescido de 30.018 quilômetros quadrados, reivindicados à Argentina na questão das Missões. A contenda foi resolvida, afinal, pelo acordo de 20 de Outubro de 1916. O Rio Grande também nos contesta um trecho ao Sul (BOITEUX, 1920, p. 20).

Pode-se dizer que o Capitão-tenente Lucas Alexandre Boiteux foi, seguramente, um dos principais responsáveis pela construção de uma narrativa sobre a história de Santa Catarina, a qual era, sobretudo, patriótica. No prefácio da Pequena História Catarinense, datado de 02 de maio de 1919, ele diz: 
Como prólogo, desejo, apenas, tomar dois trechos d'ouro de Emilio Faguet, ${ }^{6}$ nada mais.

Diz ele: 'o amor da pequena Pátria é a própria essência do patriotismo, porque a pequena Pátria é a que amamos instintivamente e que não precisa ser admirável para ser admirada nem de ser amável para ser amada'.

E: 'Pode o historiador não ser um patriota, mas, em que the pese, será um semeador de patriotas'.

Foi assim pensando que me animei a escrever o presente livrinho. Que a sagrada semente, que procuro difundir, caia em campo feraz é o meu maior anhelo.

Os membros do Instituto Histórico e Geográfico de Santa Catarina representavam os valores manifestos no projeto pedagógico republicano, ou seja, crença nas virtudes da instrução moral e cívica como forma de manter a ordem social e fortalecer o caráter nacional. No IHGSC, a afiliação em tal projeto encontrava discursivamente o sentimento de amor à "pequena pátria". Sentimento esse que, certamente, não estava descolado da Pátria mãe, como bem demonstra Lucas Boiteux em seu 'livrinho'.

Sobre essa referência ao livro, no diminutivo, gostaríamos de fazer algumas breves ponderações. A opção pela palavra Pequena e a indicação clara, de que é Ilustrada, denota o esforço do autor de, já, no título, indicar que o livro é destinado a um público diferenciado daquele do primeiro livro. A Pequena História Catarinense é, claramente, uma produção didática, no sentido que se destinava ao público escolar. Encontramos, aqui, indícios da idéia de que o saber histórico deveria ser popularizado, sua narrativa tornada mais acessível e possível de ser ensinada. $\mathrm{O}$ uso dos termos "pequena" e "livrinho" indicam apropriações de outros autores de livros didáticos de História que circulavam na época, como Rocha Pombo, por exemplo, pois, era comum que esse autor se referisse ao livros de História do Brasil, para o ensino elementar, como "pequena história" e "livrinho", sendo uma forma de se comunicar com seu público leitor: jovens e professores.

6 Auguste Émile Faguet (1847-1916), escritor e crítico literário francês, membro da Academia Francesa. 
As características narrativas de Boiteux são importantes meios de percepção da forma como eram articuladas as redes políticas e culturais no contexto das décadas iniciais do século XX. Primeiramente chamamos a atenção para a dedicatória do livro Pequena História Catarinense, feita em forma de homenagem do autor a Hercílio Luz, bem como o uso de assinaturas de alguns dos personagens político-administrativos da história catarinense à guisa de ilustração no livro. Lucas Boiteux possuía consigo uma coleção de autógrafos recolhidos pessoalmente e, muitas vezes, recortados de ofícios e documentos. Essas assinaturas eram utilizadas em suas obras a fim de legitimar os personagens de suas narrativas. Supomos que a finalidade desse uso se dava em dois níveis: de ilustração, quando da ausência de retratos ou fotografias dos mesmos, ou uma possível tentativa de fornecer status de proximidade entre o autor e os personagens narrados no livro. ${ }^{7}$ Os autógrafos acompanhavam as narrativas no corpo do texto e se constituíam, em grande parte, das ilustrações presentes. Sobre o uso das assinaturas de "personagens ilustres" e mesmo a dedicatória do livro a Herć́lio Luz - uma autoridade consolidada à época - Roger Chartier (2003), discorrendo sobre as dedicatórias e agradecimentos dispensados pelos autores às autoridades, contribui para pensarmos essa prática cultural como uma forma de captar a estima daqueles que colaboraram ou poderiam contribuir para o sucesso de uma determinada produção literária. Nesse caso, isso é bem visível, visto que foi o governo de Hercílio Luz que financiou a distribuição do livro quando assinou o decreto de sua adoção oficial.

Outro aspecto a ser destacado é o próprio diálogo existente entre os intelectuais produtores de conhecimento didático neste período, como se faz visível no trecho: "A população do Estado foi ultimamente (1916) computada em 560.000 almas pelo professor Henrique Fontes em consciencioso trabalho que publicou, sendo a razão média do crescimento anual de 272

Esse conjunto de assinaturas recolhidas e guardadas pelo autor está disponível no arquivo do Instituto Histórico e Geográfico de Santa Catarina, em Florianópolis. 
por 10.000" (1920, p. 24). O diálogo e a reafirmação entre os trabalhos publicados e produzidos pelos autores da época, além da escolha de adjetivos pomposos e textos rebuscados para a exaltação destes personagens, são características constantes nas narrativas de Boiteux.

O contexto dessa produção suscita algumas reflexões. Há marcante intenção em se forjar determinados ideais nacionais e regionais presentes nas falas destes autores (Lucas Boiteux e Henrique Fontes; sobre o último falaremos mais adiante). Ao se analisar essas produções, percebemos discursos que buscavam legitimar a participação dos então considerados "grandes personagens catarinenses” na construção do ideal de nação brasileira e do Estado catarinense naquele cenário político. Inclusive, tais personagens são caracterizados como heróis catarinenses, como é o caso da expressão utilizada por Lucas Boiteux: "Heróis Catarinenses” (1920, p. 100), em que se destaca a participação dos heróis da Marinha e do Exército no período pós-Independência.

Os discursos produzidos nas obras didáticas do início do século XX, em Santa Catarina, viabilizam certas relaçôes entre aqueles e o contexto político da publicação desses exemplares. Entre essas relações, é possível destacar o apoio de Boiteux a Hercílio Luz, que exemplifica os diálogos existentes entre as parcerias políticas assumidas no contexto da produção e publicação da obra Pequena História Catarinense: "O Dr. Hercílio Luz, empossado no governo, desbrava, com pulso forte, vontade tenaz e clara visão do futuro, novos horizontes à bela terra catarinense" (1920, p. 129-131). Outra passagem sobre o posicionamento político do autor fica visível, dada a proximidade histórica e temporal da produção do livro ao governo do Marechal Floriano, além do fato de que este, por ter sido marechal, compartilhava as armas com Boiteux que era almirante da Marinha. Estes fatores podem ter influenciado o autor a designar o governo de Floriano nas seguintes palavras: "O marechal Floriano, com uma tenacidade admirável, dia a dia se tornava mais forte, graças aos elementos que pacientemente ia acumulando" (1920, p. 126). Governo este, 
que como é sabido, foi amplamente discutido e, em alguns momentos, questionado por algumas correntes da historiografia catarinense. O marechal de "ferro" como ficou conhecido, posteriormente, não foi julgado nem condenado pelo colega militar, mas elogiado pela sua tenacidade, adjetivo que remete à firmeza, coesão e aderência. Boiteux acaba optando, em muitos casos, por caracterizar figuras políticas a partir de traços visíveis e bem aceitos, de forma a transformá-los em ilustres a partir de complementos elogiosos.

Os atores políticos em cena, especialmente no caso de Santa Catarina, eram, em sua maioria, membros de uma elite que dominava grande parte dos meios sociais e políticos no período republicano. Este domínio também alcançava as produçôes didáticas, pois membros de famílias influentes, como os Boiteux, entre eles José Arthur e, principalmente, Lucas Alexandre, participavam ativamente da produção intelectual e literária desse contexto. A reafirmação política nacional e regional é perceptível, através da leitura atenta da produção didática do período, bem como permite estabelecer relações, não só entre os discursos e o contexto político, mas ainda entre as alianças políticas existentes naquele momento que poderiam modificar-se ao longo do tempo, produzindo novos e distintos discursos. Assim, em muitos trechos das obras de Lucas Boiteux, são exaltados atores políticos ilustres do Estado catarinense, especialmente aqueles membros da força militar, combatentes do conflito contra o Paraguai, em que muitas páginas são dedicadas à homenagem dos "Heróis do Paraguai”: Álvaro de Carvalho, Brigadeiro Bittencourt, Barão de Iguatemy, Fernando Machado, Almirante Proença, General Resin, Pedro Soares, Almirante Marques Guimarães e Marechal Câmara (1920 p. 115).

O uso da expressão 'herói', entre outras ilustres e honoráveis, é freqüente, tanto para designar os personagens de uma história catarinense dos dias de outrora como para reafirmar os novos personagens influentes do período vivido pelo autor, o qual foi repleto de transformações e inseguranças políticas e sociais. Os parceiros políticos, de ofício e os parceiros sócio-culturais são, em sua maioria, designados ou referenciados com adjetivos 
pomposos que os tornam prestigiosos personagens de sua narrativa. Não muito diferente do que ocorria com a produção didática do mesmo período, conforme destaca Circe Bittencourt: "A História Política que predominou no ensino de História até recentemente foi responsável pela configuração de uma galeria de personagens da vida administrativa do país” (2004, p. 77).

Pode-se afirmar que o livro Pequena História Catarinense deixa bastante evidente que a história de Santa Catarina só passa a existir após o "nascimento" da própria história do Brasil que, por sua vez, inicia indubitavelmente pela "descoberta". Ou seja, a história catarinense começa após o leitor se inteirar da "descoberta da América”, do "Tratado de Tordesilhas” e a fundação do Brasil, representado pelo seu descobrimento. Privilegiam-se, também, como personagens da história 'catarinense' mais significativos, os nomes que faziam parte da vida administrativa e política do país e do Estado, como por exemplo: Tomé de Souza, Pedro Álvares Cabral, Pero Lopes, Dias Velho.

No livro Notas para a História Catarinense - anterior ao Pequena História Catarinense - o autor constrói uma narrativa rica em detalhes, detendo-se em muitos aspectos característicos da morfologia e da geografia do território catarinense. Esse livro possui um caráter intimista em relação a determinados acontecimentos. Isso por que, em alguns momentos, a narrativa é construída a partir de 'curiosidades' acerca de determinados fatos. Há singelas passagens em que autor se preocupa em mencionar a participação das mulheres no processo histórico vivenciado em Santa Catarina e, no trecho baixo, especificamente, além de aludir tal contribuição das mulheres, o autor ainda aproveita para "alfinetar" o descaso público com a bandeira nacional:

As senhoras catarinenses, mostrando também o seu grande entusiasmo pela causa sagrada do Brasil, bordaram uma linda bandeira nacional, que ofereceram ao brioso $25^{\circ}$ Batalhão de Voluntários. Esta bandeira existe ainda guardada na Superintendência Municipal da Capital, porém, em misero estado de conservação, pois um dos Superintendentes do atual regime cometeu o crime de despojá-la de seus cordões e estrelas de ouro para com eles adornar os bonés dos fiscais!!! Misero farrapo 
glorioso, digna e honrosa representação da bravura catarinense, a que te reduziram! (1912, p. 371).

Este trecho é visivelmente rico, pois além de caracterizar uma mulher cidadã, entusiasmada como prestadora de serviços manuais, trata também de possíveis 'rixas' políticas existentes nesse contexto, especialmente quando ele utiliza a expressão "actual regimen", pois não se esforçou em citar os nomes de tais presenças políticas, nem de rebuscá-los com elogios. Estas ligeiras, porém significativas participações, narradas por Boiteux, ajudam a traçar importantes considerações acerca do convívio político e social catarinense, bem como, perceber como estes detalhes auxiliavam na composição de um conjunto de práticas vividas e experimentadas na história de Santa Catarina. Mais do que isso, a diminuição ou quase ausência dessa riqueza de detalhes na sua obra seguinte, Pequena História Catarinense, denota preocupação com determinados aspectos políticos em possível detrimento de alguns.

A atenção volta-se, muitas vezes, para a obra Notas para História Catarinense, a qual carrega em si características narrativas, pois apresenta uma riqueza descritiva e analítica maior. Esta obra contém grande número de comentários e considerações que se fazem ausentes na obra posterior; por não ser didática, Notas para História Catarinense (1912) desenvolve determinadas temáticas com maior profundidade, o que enriquece a presente análise, uma vez que o livro Pequena Historia Catarinense (1920) trata de uma versão resumida da obra anterior. $\mathrm{O}$ contraponto entre fragmentos de uma ou de outra narrativa nas obras é possível também, pois possibilita medir de que forma foi operada tal adaptação a uma finalidade didática.

Além do livro de Boiteux, na década de 1920, outra produção didática que ensinaria os catarinenses a serem catarinenses e brasileiros, foi a Série Fontes, coleção de autoria de Henrique da Silva Fontes (1885-1966), distribuída gratuitamente na rede de Instrução Pública de Santa Catarina e adotada nos estabelecimentos de ensino privados, entre a década de 1920 a 1950. Embora a Série 
Fontes não tenha sido uma produção voltada ao ensino de História, seus textos de leitura sugerem apropriações de determinadas memórias sobre História e sobre Santa Catarina que nos ajudam a pensar sobre o processo de didatização desses saberes.

Antes de passarmos a Série Fontes, cabe uma importante consideração. Mesmo após a reforma de 1911, a edição do Programa de Ensino para os Grupos Escolares de 1920, e o decreto que tornou oficial a adoção da Pequena História Catarinense, tanto no curso da Escola Normal Catarinense como nos quartos anos dos Grupos escolares, as primeiras décadas do século XX foram marcadas pela escassez de produção e circulação de obras sobre a história de Santa Catarina. Isso se deve, em parte, pela constituição tardia (em relação aos demais Estados do Sul e do Sudeste) de uma chamada rede editorial no Estado, algo que só se efetivaria a partir da década de 1980, cujo marco foi a implantação da Editora da UFSC (HALLEWELL, 2005). Na ausência de uma rede editorial, mesmo com a presença da tipografia em Santa Catarina, desde a década de 1830, foi o Estado que se ocupou do financiamento da produção e circulação das obras relativas à história local e/ou regional na primeira metade do século XX, condição que guarda resíduos e se faz atual. A maior parte dos livros de história dos municípios é financiada pelas prefeituras e os livros didáticos de História de Santa Catarina, publicados exclusivamente com o financiamento do Estado ainda são uma realidade, por exemplo.

Henrique da Silva Fontes (1885-1966) foi um homem público que ocupou diversos cargos de reconhecida relevância política no Estado. Sócio do IHGSC, na década de 1930 ocuparia sua presidência, exercendo um longo mandato de 1935 a 1965. Bastante ligado à educação, foi, entre 1919 e 1926, Diretor da Instrução Pública em Santa Catarina, período em que a Série foi indicada para a instrução primária nas escolas do Estado. Foi personalidade marcante durante o processo de transformação da instrução pública em Santa Catarina, ocupando também cargo de inspetor de ensino durante anos. As redes mobilizadas, entre os autores 
didáticos aqui pensados, Henrique e Lucas, no Estado catarinense, também se tornam importantes meios de percebermos a forma como eram construídas as suas narrativas.

A Série Fontes trazia consigo muitos discursos e elementos que buscariam destacar algumas das figuras políticas influentes, mitificando suas ações e produzindo heróis propriamente catarinenses. O formato de cartilhas, como a Série Fontes, trouxe inovações que adentravam diferentes âmbitos da educação infanto-juvenil. As páginas eram repletas de liçôes de cidadania, higiene, postura e comportamento, permeadas e circunscritas nas lições, sob diferentes temas. Mais do que isso, as cartilhas e livros de leituras populares buscavam forjar, em suas páginas, a figura de um "leitorcidadão" brasileiro, o qual deveria orgulhar-se de sua nação, de seus heróis e de seus mitos, estando a par de seu passado glorioso e participando ativamente do constante crescimento de sua pátria. Assim, o conteúdo histórico com seus mitos e heróis transformados em enfeitadas sentenças vinha acompanhado de dicas e verdadeiros ensinamentos sobre postura e cidadania.

Quanto à autoria dos textos, de acordo com Vanderlei Machado (2009, p. 57), "além de se inspirar, Henrique Fontes compilou textos destes e de outros autores de grande influência na sociedade da época que se bateram pela causa do ensino e pelo combate ao analfabetismo". Conforme indica Machado, em certos textos não foi possível identificar os autores, pois é provável que sejam de autoria do próprio professor Fontes. Machado acrescenta que esta "inferência se deve ao fato de que alguns escritos, publicados na forma de correspondência, são assinados com os mesmos nomes dos filhos do autor, nascidos até o ano da publicação do Primeiro Livro de Leitura em 1920" (2009, p. 57). No que tange à circulação e ao público destinado à leitura dos livros da Série Fontes, pode-se perceber que Henrique Fontes afirmou buscar a qualidade do material didático por ele elaborado, adequando-o às diretrizes pedagógicas que norteavam a escola naquele contexto. Os livros de leitura da Série Fontes e os ensinamentos neles contidos, segundo o autor de mesmo nome, 
"não eram direcionados unicamente para a parcela mais pobre da população, a chamada classe popular, mas também para os "remediados", ou seja, à classe média urbana de Florianópolis" (apud MACHADO, 2009, p. 58).

Especialmente no que toca os heróis, nas palavras do próprio Henrique Fontes, em seu Terceiro Livro da Série:

Todos os progressos alcançados depois são o resultante do patriótico esforço dos homens de 1822. Foi uma geração de fortes. Nomeá-los todos é difícil. José Bonifácio de Andrade e Silva, Padre Diogo Feijó, Clemente Pereira, Evaristo da Veia simbolizam essa plêiade ilustre de abnegados patriotas, que nos diversos momentos da História, concretizam a aspiração nacional (FONTES, 1929, p. 77-78).

Diferentes textos - em meio às lições de civilidade - informam os acontecimentos e personagens históricos mais significativos da época:

No dia 22 de abril do ano de 1500 Pedro Álvares Cabral descobriu o Brasil [...] Outra missa foi celebrada no dia 1 de maio, em terra firme, com muita pompa e em presença dos índios, que, em grande número, espantados, assistiram às cerimônias. Esta cena deu assunto para o famoso quadro "A primeira missa do Brasil", de que é autor o catarinense Vitor Meirelles (FONTES, 1935, p. 60-61).

Na década de 1930, vemos evidências de dispositivos buscando fixar datas e acontecimentos fundantes, inaugurais de nossa História, circularem em Santa Catarina:

[...] 3 de maio é o dia em que se festeja o descobrimento do Brasil. Este fato, como já vimos, ocorreu a 22 de abril de 1500, mas até hoje se conserva a festa no dia 3 de maio, no qual os antigos colonos pensavam que tinha sido descoberto o Brasil (FONTES, 1935, p. 131-132).

Na Série Fontes observamos, em diferentes situações, a data de 03 de maio como data do descobrimento do Brasil. Memória que será substituída pela de 22 de abril, como faz questão de explicar o próprio Henrique Fontes, suposto autor ${ }^{8}$ do referido

8 Há poucos textos sem indicação de autoria nos quatro livros da Série Fontes; parte desses textos, supóe-se, ser de autoria do próprio Henrique da Silva Fontes. 
texto. A data de 03 de maio (a referência seria em homenagem ao dia da Santa Cruz) aparece em vários livros de História do Brasil, mas vai sendo, aos poucos, substituída pela de 22 de abril, à medida que a carta de Pero Vaz de Caminha ganha status de certidão de nascimento do Brasil.

Na Série Fontes, há, claro, espaço para as ilustres figuras do Estado, como nesse texto de Edmundo da Luz Pinto, no quarto livro da Série:

A vida de Felipe Schmidt foi uma edificante lição que deveria ser meditada, em meio a confusão de valores que caracteriza a atualidade brasileira. Era a de um homem, em quem, pela austeridade, pela sinceridade, pela lealdade, pela elevação dos seus propósitos, parecia estar encarnada a própria dignidade; era a de um cidadão integro e patriota. $[. ..] \mathrm{O}$ sangue germânico, que the corria nas veias, através e tantas gerações, não impediu que ele fosse profundamente brasileiro (FONTES, 1930, p. 135-136).

No texto de Osório Duque Estrada, "Heroínas Brasileiras", que consta no quarto livro da Série, Anita Garibaldi aparece entre as raras heroínas:

Muitas foram as mulheres brasileiras que deram provas de grande patriotismo, assinalando-se por atos de bravura nas diversas guerras que sustentamos desde o período colonial. Ao nome legendário de Anita Garibaldi, que se cobriu também de glórias na Itália, registra a história de Clara Camarão, Anna Nery, Baronesa de Porto Carrero e varias outras (FONTES, 1930, p. 59).

Em relação às mulheres, cabe destacar que somente aquelas que são reconhecidas como personagens de "grandes feitos" e sacrifícios pela pátria merecem ser citadas nessas produções. Os textos dos livros didáticos - nas primeiras décadas do século XX - exaltavam os cidadãos e não as cidadãs. Os cidadãos de valor, que amavam a pátria e que seriam capazes de lutar por ela, eramos trabalhadores, os grandes vultos da política, da economia, que recebiam total atenção nessas abordagens. Inclusive, na publicação de Boiteux, Pequena História Catarinense, a única passagem encontrada nesta obra que foi dedicada ao destaque de alguma participação 
feminina, na narrativa de uma história de Santa Catarina, encontra-se na citação a seguir, na qual o autor menciona a participação de algumas voluntárias na Campanha Abolicionista, ocorrida no Estado, por volta de fins do século XIX: "A mulher catarinense, dando uma demonstração de seus alevantados sentimentos, veio prestar desinteressado apoio à magnânima idéia” (1920, p. 119).

A nação deveria ser legitimada através da História, e os materiais didáticos produzidos neste e nos momentos posteriores carregam consigo estas intenções. Uma história única e verdadeira, com seus heróis e mitos, a fim de se criar uma nação estável, unificada e a par de seu passado glorioso, com uma intencionalidade de se buscar um futuro próspero, regional inserido legitimamente dentro do recorte nacional. A História, enquanto campo disciplinar, tornou-se o meio legítimo de divulgação destes grandes homens e de seus feitos, e o culto dos heróis nacionais e regionais toma forma nas páginas destes materiais didáticos.

\section{Algumas considerações finais}

O livro didático - objeto e produto cultural - inscreve-se numa longa tradição, portando um sistema de valores bastante complexo, composto por idéias e uma cultura própria. Assim, não deve ser pensado de forma separada das circunstâncias e das condições históricas de seu tempo. Historicamente vem sendo alvo constante de vigilâncias e de críticas, porém não se pode discordar do importante espaço ocupado por este impresso na História e no processo de escolarização no Brasil. Tal a importância desses materiais, na formação escolar, que se constituíram em importantes meios na reafirmação do nacionalismo e da pátria brasileira e, no presente estudo, numa perspectiva mais regional, como a representação de pequena pátria.

Os estudos do autor Paulo Miceli (1994), em sua obra "O mito do herói nacional”, trazem importantes questões sobre a presença de heróis e mitos dentro das narrativas didáticas utilizadas em 
sala de aula. Ele afirma que a nação não trata de algo dado e pronto para todo o sempre, mas depende da criação constante para que possa durar e para que as pessoas acreditem nela. Os livros didáticos e o ambiente escolar, portanto, segundo o autor, são formas eficazes para se perpetuar valores, convenções e concepções de nacionalismo e nação. Segundo Miceli, muitos professores acabavam ou ainda reproduzem seus conteúdos numa abordagem que, dificilmente, foge das palavras e sentenças sabiamente construídas, forjadas e utilizadas por seus autores.

Por meio de pesquisas realizadas em escolas com 267 estudantes da sexta série do Ensino Fundamental à terceira série do Ensino Médio, Paulo Miceli fez questionários baseados em questões simples como: Quem é o seu herói favorito? Como ele é? Por que é um herói? O que é um herói? As respostas a estas perguntas compuseram um rico banco de dados, capaz de fornecer importantes interpretações a muitos pesquisadores que se interessarem por esta temática. É, no mínimo, notável, o quanto os manuais didáticos e o contato com estas informações e construções em sala de aula conseguem produzir e incutir na opinião destes alunos muitas concepções de heróis e seus mitos. Alguns, freqüentemente apontados pela maioria dos alunos, como é o caso de Tiradentes e Dom Pedro I, fornecem pistas de como são forjadas as características e posturas idealizadas e que remontam à perfeição dos mesmos, o que nem sempre condiz com estudos e interpretaçôes realizadas nos âmbitos acadêmicos.

Os feitos fantásticos e atos de coragem por causas maiores e defesa da nação brasileira são constantes abordagens destes materiais. Tiradentes, Dom Pedro I, entre as outras figuras populares dos livros de história, são freqüentemente considerados heróis nacionais, mesmo que, no caso de Tiradentes, seja uma construção bem posterior à sua existência. A própria concepção de quem é ou não herói instiga o debate, pois, a partir do momento em que é exaltada uma determinada ação ou personagem, ocultam-se e apagam-se muitas outras participações. 
A produção contemporânea sobre História Regional, principalmente aquela para ser consumida, dada a ler nas primeiras séries do ensino fundamental ainda segue, (re)fundando aspectos recortados da história catarinense que foi produzida no início do século XX. Há livros que até iniciam pelos sambaquianos que habitavam o litoral, mas, em seguida, reportam-se às navegações, ou seja, a história de Santa Catarina segue narrada para as crianças e jovens, ainda, através de um recorte político-administrativo nacional que se sobrepõe ao regional.

Nesse sentido, consideramos irrenunciável interpretar a construção dessa história como uma 'realidade dada a ler'. A construção da história como disciplina e construção de uma saber histórico escolar - e sua divulgação - certamente não estão restritas aos livros didáticos. Claro está que muitos outros aspectos devem ser levados em consideração, os quais atravessam e constituem a cultura escolar. Contudo, partindo do pressuposto de que "a história do ensino de História e a história da disciplina escolar se cruzam, entrecortadas pelo debate político e historiográfico e pela produção de material didático, sobretudo os livros escolares" (FONSECA, 2006, p. 12), os estudos acerca do ensino de História realizados priorizam suscitar a análise de diferentes objetos, fontes, linguagens e abordagens utilizadas na produção do conhecimento histórico escolar. Sobre o ensino de História de Santa Catarina, há, ainda, muito a ser pesquisado, interpretado e problematizado, especialmente naquilo que se refere à produção dos discursos sobre uma história pretensamente catarinense, singular, veiculada nos manuais didáticos e em consonância com os enfrentamentos e discursos políticos hegemônicos. Nesse artigo, apresentamos apenas algumas questões preliminares, com análises e interpretações ainda em aberto, sujeitas a revisões e mudanças que, certamente, serão feitas com a continuidade da pesquisa. 


\section{Referências}

ABUD, Kátia. Currículos de história e políticas públicas: os programas de História do Brasil na escola secundária. In: BITTENCOURT, Circe (Org.). O Saber Histórico na sala de aula. São Paulo: Contexto, 2005.

BITTENCOURT, Circe. Ensino de História: fundamentos e métodos. São Paulo: Cortez, 2004.

Horizonte: Autêntica, 2008.

. Livro didático e saber escolar (1810-1910). Belo . O saber histórico em sala de aula. São Paulo: Contexto, 2005.

. Os confrontos de uma disciplina escolar: da história sagrada à história profana. Revista Brasileira de História, São Paulo, v. 13, n. 25-26, set. 92/ago. 1993, p. 193-221.

BOITEUX, Lucas Alexandre. Notas para a História catarinense. Florianópolis: Typ. a vapor da Livraria Moderna, 1912.

. Pequena História Catharinense. Ilustrada. Florianópolis: Officinas a Electricidade da Imprensa Oficial, 1920.

CHARTIER, Roger. A História Cultural: entre práticas e representações. Lisboa. Rio: DIFEL: Bertrand Brasil, 1990.

. Formas e sentidos - cultura escrita: entre distinção e apropriação. São Paulo: Mercado de Letras, 2003.

CARRETERO, Mario; ROSA, Alberto; GONZÁLEZ, Maria Fernanda (Orgs.). Ensino de História e Memória Coletiva. Porto Alegre: Artmed, 2007.

CORRÊA, Carlos Humberto Pederneiras. História da Cultura Catarimense: o Estado e as Idéias. Florianópolis: UFSC, 1997.

CHOPIN, Alain. História dos livros e das edições didáticas: sobre o estado da arte. Educação e Pesquisa, Revista da Faculdade de Educação da USP, São Paulo, v. 30, n. 3, p. 549-566, set./dez. 2004.

DALLABRIDA, Norberto. A fabricação escolar das elites: o Ginásio Catarinense na primeira república. Florianópolis: Cidade Futura, 2001. 
FIORI, Neide Almeida. Aspectos da evolução do ensino público. Ensino público e política de assimilação cultural no Estado de Santa Catarina nos períodos imperial e republicano. 2 ed. Florianópolis: UFSC, 1991.

FONSECA, Thais Nívia de Lima. História es Ensino de História. 2 ed. Belo Horizonte: Autêntica, 2006.

FONTES, Henrique da Silva. Cartilha Popular. Florianópolis: Cysne, 1920.

nópolis: Cysne, 1921.

. Série FONTES. Primeiro Livro de Leitura. Floria-

. Série FONTES. Segundo Livro de Leitura. Florianópolis: Imprensa Oficial do Estado, 1935.

. Série FONTES. Terceiro Livro de Leitura. Florianópolis: Livraria Moderna, 1929.

. Série FONTES. Quarto Livro de Leitura. Florianópolis: Livraria Moderna, 1930.

GASPARELLO, Arlette Medeiros. Construtores de identidades: a pedagogia da nação na escola secundária brasileira. São Paulo: Iglu, 2004.

GOMES, Ângela de Castro. A República, a História e o IHGB. Belo Horizonte: Argumentum, 2009.

GONÇALVES, Janice. Sombrios umbrais a transpor: arquivos e historiografia em Santa Catarina no século XX. 2006. 2 v. Tese (Doutorado) - Universidade de São Paulo. Faculdade de Filosofia, Letras e Ciências Humanas. Programa de Pós-Graduação em História Social.

HALLEWELL, Laurence. O livro no Brasil: sua história. 2 ed. São Paulo: EDUSP, 2005.

JULIA, Dominique. A Cultura escolar como objeto histórico. Revista Brasileira de História da Educação, São Paulo, n. 1, p. 09-43, jan./jun. 2001.

MACHADO, Vanderlei. Menino não chora: representações de corpo e gênero na escola primária catarinense. Revista Linhas, Florianópolis, v. 10, n. 1, p. 54-72, 2009. 
MICELI, Paulo. $O$ mito do herói nacional. 5 ed. São Paulo: Contexto, 1994.

MOACYR, Primitivo. A instrução e as provincias (Subsídios para a história da educação no Brasil) 1834-1889. v. 3. Espírito Santo, Minas Gerais, Paraná, Santa Catarina, Rio Grande do Sul e Goiás. São Paulo: Companhia Editora Nacional, 1940.

SANTA CATARINA. Lei n.1.144 de 30 de setembro de 1886. Arquivo Assembléia Legislativa do Estado de Santa Catarina, em Florianópolis, 1986.

- Relatório do Sr. Coronel Augusto e Souza. Abertura da $\mathrm{1}^{\mathrm{a}}$ Sessão da $27^{\mathrm{a}}$ legislatura da Assembléia Provincial em $1^{\mathrm{o}}$ de setembro de 1888. Desterro (SC).

- Programa de ensino dos Grupos Escolares - Aprovado pelo decreto n. 1.322, de 29 de janeiro de 1920, Florianópolis, 1920. 